\title{
Depression-Level Effectiveness of the Curse Words in Young Adults in Pune University
}

\author{
Rahul A Hajare* \\ Department of Health Research Indian Council of Medical Research, India
}

Received: 眥 June 01, 2018; Published: 盋June 11, 2018

*Corresponding author: Rahul A Hajare, ICMR Post Doc, Indian Council of Medical Research, New Delhi, India

\begin{abstract}
Depression and substance abuse has on the increase all over the world. The poor and the rich are also involved in this dangerous habit that has impact not only on reproductive health but also has an impact on family, society, increase in health care expense and increased criminal activity. Health care providers have more concerned with treating the victims and less concerned on its prevention. Pregnant women bear a greater brunt and there has adverse pregnancy outcome. Low birth weight, preterm labour, increased in miscarriage and raised perinatal mortality has some of the adverse effects. Children of such parents have more likely to inherit this bad trait. Children living in abusive homes where drugs and alcohol abuse occur simultaneously has often deprived of more than just the basics of food and shelter. Depression has, any act on the part of the husband, partner or family which causes physical, mental, social or psychological trauma to the woman and prevent shier from developing her personality. Reason for the increase in depression violence has; urbanization, industrialization, growth of urban slums, co-education and co-working in offices and factories, modern movies, television, obscene and pornographic literature and decreasing religious restrictions.
\end{abstract}

Keywords: Cursing; Depression; Anger; Young adults; Curse words abuse

\section{Introduction}

As we aware sex lives in unhealthy brain (Figure 1). The research investigated whether young adults use of curse words have related to depression a danger. Prior research has suggested links between the use of curse words and anger and between depression and anger [1,2]. In a large study involving university undergraduates, we assessed depression, frequency of curse word usage, and expressive anger. The results showed that for women, but not men, the relationship between the use of curse words and depression has mediated by anger [3,4]. Cursing has significantly related to depression in men. These results suggest that the use of curse words may be useful in identifying men experiencing depression symptoms non-clinical investigation in privately manage co-educational pharmaceutical institution in pune university. Implications for using verbal behaviours as indicators of depression have discussed. Prior research has shown that anger can be a major symptom in those experiencing depression. Verbal behaviour has an important source of information about individuals seeking mental health treatment, such as those seeking treatment for depressions. The focus of the present research has to investigate the extent to which depression lead to the use of some forms of verbal behaviour, such as use of curse words examination had been done dilation of pupil, skin tone of women.

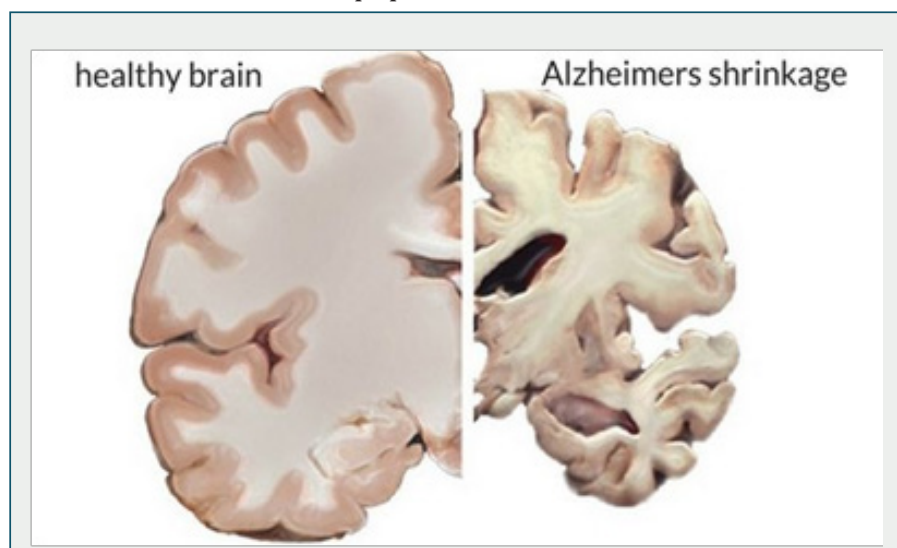

Figure 1: Healthy brain \& Alzheimers shrinkage.

The effects that depression has on both the individual and society had far-reaching. Depression significantly decreases quality 
of life at the individual level. Recent economic analyses have shown that the cost of major depressive disorder in the India particular pharmacy institution in private for personal benefit has goes up in 2017, taking into account direct, suicide-related, and workplace costs. Factors such as decreased productivity at work and increased health care costs to employers have increased over time as depressive disorders have become more widespread. The World Health Organization estimates that depression will be the second most prevalent disorder in the world if it continues to increase at the current rate (WHO, 2016).According to the Diagnostic and Statistical Manual- Fifth Edition (2013), major depressive disorder (MDD) and related depressive disorders have characterized by persistent. Depression has also a relationship between age variation in heterosexual attraction and using depressive words to expressed forced sex and abuse habit [5,6]. Depressive symptoms that affect normal functioning, such as loss of interest or pleasure, loss of happiness, loss good looking, loss of easy smile, dirt body smell, unhygienic staff, and loss of health principal in previously enjoyed activities and disturbance of mood and acidity personality, personality of urine disorder and cancer prone personality has also an extended cause of depression in middle age staff of pharmacy institution. A variety of other possible symptoms such as change in weight or appetite, disordered sleep, and fatigue, skin rashes and lupus may also present. Major depressive disorder has characterized by symptomology for at least two weeks, whereas longer lasting mood disorders such as persistent depressive disorder (previously medical science called dysthymia) can last for up to five years, with depressive symptoms similar to MDD.

Depression occurs with a variety of other psychological and physical conditions, such as anxiety and chronic illness that can accept by the body structure, body asymmetry and body line. Young adults such as college students have diagnosed with depression at a very high rate, and depression has been identified as the number one health problem among college students cannot ignored. Not everyone who has depressed seeks treatment or perceives the need to seek treatment. Lack of treatment leads to decreased quality of life and increased economic burden associated with depressive disorders. Current estimates suggest that of individuals who have experiencing depressive symptoms, only 70-75\% seeks treatment, data shows National Association of Psychological Science India (Regd.). Common reasons for not seeking treatment include inability to access treatment due to financial or untold, stigma due to cultural expectations, embarrassment; or a need to cope with issues internally without the help of others. Alternatively, some individuals may not perceive the severity of their depressive symptoms to be great enough to seek treatment. While symptoms such as low mood, fatigue, and sleep issues, inability of love has somewhat commonly known to be associated with depression, there have some symptom patterns that may not be as familiar. For example, lack of ability to concentrate, memory problems, and physical symptoms such as gastrointestinal issues or migraines can also be indicators of depression. Irritability and anger can be symptoms of depression. Externalizing behaviours such as these maybe expressed as selfdestructive behaviour, such as risk-taking and substance abuse, especially for men. It has been well documented that there has sex differences in the symptoms of depression unawareness of love sex $[7,8]$. Women has more likely to exhibit higher levels of internalizing symptoms (e.g., stress, rumination), while males have more likely to exhibit more externalizing symptoms (e.g., aggression).

In addition, women have more frequently diagnosed with depressive disorders and depressive symptoms for females have found to be more severe that comes under not to true principal of health. In a 2015 study, college of pharmacy Pune University found that, in a large sample of individuals diagnosed with Major Depressive Disorder (MDD) females had higher reported levels of comorbidity and symptom severity including symptoms such as: weight gain, anxiety, and suicidal ideation. It has been suggested that the increased negative symptomology experienced by females when compared to males might be due to ovarian hormones and varying levels of sensitivity to adrenal hormones in the hypothalamic-pituitary-adrenal (HPA) axis when exposed to stress. Other explanations pertaining to the sex-differences between depression symptoms and behaviour have focused largely on cultural gender socialization. Specifically, in western cultures, males have more frequently socialized to believe that it has more socially acceptable to exhibit anger while females have not this could be why depressed males engage in more externalizing symptoms (i.e., aggression) than females.

The purpose of the present research has to test the hypothesis non-clinical investigation that individuals who have experiencing depression symptoms produce some forms of verbal behaviours, such as use of curse words. We further hypothesized that the relationship between cursing and depression may be mediated by anger. Separate lines of research have shown that anger has related to depression and that anger has related to cursing with higher levels of anger related to higher levels of both depression and cursing. The body of literature documenting the relationship between anger and depression has vast. The link between anger and depression has known. The degree of anger and severity of depression has positively correlated. Aggression, irritability, and hostility has related terms that refer to anger directed outwardly $[9,10]$. The cognitive act of rumination mediated the relationship between depression and anger in nonclinical community sample of adults, suggesting that anger and depression interact in a way that has characterized by both internal and external manifestations. Indeed, found that cognitive components of anger/hostility predicted increases in depression among a sample of nonclinical older adults. Anger mediated the relationship between college students' emotion regulation abilities and their depression. The students have a nonclinical sample, similar to the one reported in the present study. The relationship between anger and cursing has been substantially examined as well. Primary purpose of cursing is 
to express emotions such as anger, and to portray that emotion to others through the verbal behaviour of cursing. Cursing has been shown to have a dampening effect on intense feelings of anger and frustration, providing an outlet for expression without requiring the person to necessarily engage in aggressive physical acts to channel the emotion. Points out that the intensity of curse words can be adjusted [11,12].

\section{Methods}

\section{Participants}

Fifty five (20 women, 25 men) undergraduates who has enrolled in courses in the department Pune University Pune participated in exchange for course credit. The sample has $8 \%$ White, $5 \%$ Black, $6 \%$ Obese; $5 \%$ unsymmetrical body; $1 \%$ living with poor sanitation and $1 \%$ alcohol dependent. Sixty five percent of the sample reported high family income to be 60,000 or more.

\section{Materials}

Participants completed survey in which the use of curse words, depression symptoms, anger, and demographics have assessed. We assessed participants' use of curse words using the self-report method described by researcher (2017). Participants have asked to rate the frequency with which they used 10 curse words used frequently by Marathi speakers (i.e., Bhikari, do not respect, fake smile, showing up high style, do not come to college, what do you want, forcefully sign, go to home, come with your father, second nature). Frequency of usage has rated on a 6-pointscale ( 1 = never, 2 = rarely, as in once or twice a year, $3=$ occasionally, as in once or twice a month, 4 = about once or twice a week, $5=$ about once or twice a day, and $6=$ three to five times day, and $7=$ more than five times a day).

\section{Procedure}

Participants viewed the invitation to participate in the study on SONA, which directed them to the survey which has implemented with a professional license ofSurveymonkey.com. Additional information collected from college muster, signature style, colour of signature, font size and treatment received by administrative officer while signed the muster.

\section{Data Collection}

Data has collected using a 10-item semi-structured questionnaire administered one-on-one in private by a trained male female staffs study team member. The questionnaire has informed by prior studies examining determinants of depression experience in other settings, piloted in 8 individuals, and modified accordingly to better achieve the aims of the study. The primary outcome, past 3-month experience of depression perpetrated by either the participant's senior or a member of the approve assistant professor, has measured using the small city mind set depression and control. That has a culturally-tailored depression measure, composed of 105 items informed by qualitative interviews with community members and individuals working directly with depression survivors in Pune University pharmaceutical Institutions living with poor sanitation (PUPILPS) that surveys control, psychological, physical, pupil dilations and mind script, and has validated in married male female staffs residing in Pune Pharmaceutical Institutions. Potential correlates of depression experience (Table 1) and (Figure 2) has surveyed across 10 domains:

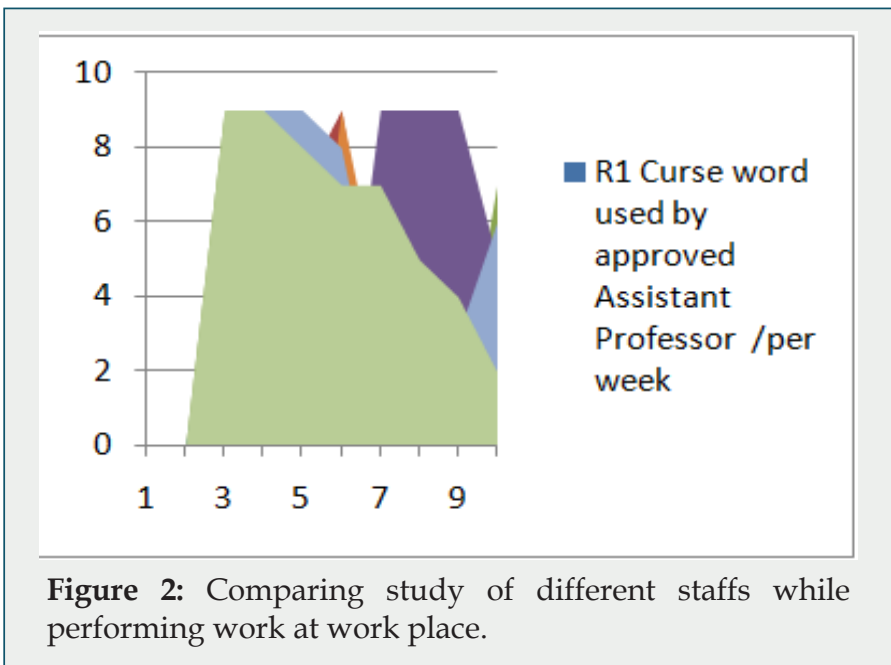

Table 1: Modified and Inter \& Intra Relationship of Different staffs against curse words.

\begin{tabular}{|c|c|c|c|c|c|c|c|c|}
\hline R1 & $\mathrm{R} 2$ & R3 & R4 & R5 & R6 & R7 & R8 & R9 \\
\hline $\begin{array}{c}\text { Curse word } \\
\text { used by } \\
\text { approvedAssistant } \\
\text { Professor /per } \\
\text { week }\end{array}$ & $\begin{array}{l}\text { Curse word } \\
\text { used by } \\
\text { senior staffs } \\
\text { (Male \& } \\
\text { Female) / } \\
\text { per month }\end{array}$ & $\begin{array}{l}\text { Curse word } \\
\text { used by } \\
\text { Principal / } \\
\text { Meeting\& } \\
\text { short } \\
\text { meeting } \\
\text { alternatively }\end{array}$ & $\begin{array}{c}\text { Curse } \\
\text { word used } \\
\text { by HOD/ } \\
\text { Theory } \\
\text { Examination }\end{array}$ & $\begin{array}{c}\text { Curse } \\
\text { word used } \\
\text { by HOD/ } \\
\text { Practical } \\
\text { Examination }\end{array}$ & $\begin{array}{l}\text { Curse word } \\
\text { used by } \\
\text { Examination } \\
\text { Incharge } \\
\text { / Theory } \\
\text { \&Practical } \\
\text { Examination }\end{array}$ & $\begin{array}{c}\text { Curse } \\
\text { word used } \\
\text { by senior } \\
\text { female } \\
\text { staffs / } \\
\text { Engaged } \\
\text { extra } \\
\text { workload }\end{array}$ & $\begin{array}{l}\text { Curse word } \\
\text { used by } \\
\text { Administrative } \\
\text { Officer/ Month }\end{array}$ & $\begin{array}{c}\text { Curse } \\
\text { word used } \\
\text { Principal } \\
\text { /Theory } \\
\text { Examination }\end{array}$ \\
\hline 1 & 1 & 9 & 1 & 6 & 1 & 1 & 3 & 9 \\
\hline 3 & 8 & 4 & 1 & 3 & 1 & 9 & 0 & 9 \\
\hline 1 & 7 & 2 & 1 & 1 & 1 & 9 & 5 & 8 \\
\hline 2 & 9 & 1 & 1 & 7 & 9 & 8 & 0 & 7 \\
\hline
\end{tabular}




\begin{tabular}{|l|l|l|l|l|l|l|l|l|}
\hline 4 & 3 & 6 & 9 & 3 & 4 & 3 & 1 & 7 \\
\hline 2 & 7 & 3 & 9 & 1 & 2 & 2 & 3 & 5 \\
\hline 1 & 4 & 1 & 9 & 0 & 3 & 3 & 2 & 4 \\
\hline 0 & 2 & 7 & 5 & 0 & 2 & 6 & 2 & 2 \\
\hline
\end{tabular}

a) Socio-demographics

b) Depression conceptualization and acceptance

c) The marital relationship and marital family relationship

d) Telephonic communication and behaviours

e) Sexual attraction

f) Reproductive health

g) Staffs abuse and gambling

h) Stress

i) Resilience

j) Social support

\section{Results}

A number of variables have dropped from consideration due to collinearity. In choosing between variables, those with greater correlation with the outcome has used. For example, age and education of the respondent has both associated with age and education of the staffs; therefore, the staff's variables have used. Similarly, the amount of premarital contact has associated with how well the participant felt. A multivariable model for Domain R6 from curse word used by examination In charge / theory \& practical examination has not run longer because after accounting for collinearity, only this variable, capacity to communicate willingness to have approval power., that domain has a candidate prior 3-month betting and gambling has excluded from the final model because of the low frequency of affirmative response. The final model has shown in domain R 10 In the result, depression experience has significantly associated with less educational attainment by the participant's staffs, less satisfaction of the family with the maintain they received at the time of work, poorer conflict negotiation skills, and greater acknowledgement of depression occurrence in family and friends. The research examined the relationships among use of curse words, anger, and depression symptoms in order to determine whether cursing may be predictive of depression symptoms in young adults.

The results confirmed that for women, the relationship between use of curse words and depression symptoms was mediated fully by expressive anger. For men, the relationship between depression and use of curse words was not significant. The present research had many similarities in findings with previous research. First and foremost, the present study found that females reported higher levels of depression than males. I would like to request Honourable Present Prime Minister of India to stop approval of course who has poor level sanitation, low level oxygen uptake, abuse words used by head of the department, I would also like to request Honourable present prime minister to check the Ashaaram pattern in private Pharmaceutical Institution in Pune University. Alcohol dependency from adult men in service privately managed pharmaceutical institutions and not allow licence to permit open a wine shop nearer to pharmaceutical Institutions.

\section{Conclusion}

Use a plant based protein blend diet pea - lowers levels of hunger hormone, ghrelin. Quinoa -chock full of anti-inflammatory compounds called flavonoids. Hemp - contains 20 amino acids, healthy omega fats and fiber (including 9 the body cannot make on its own). Coconut - packed full of healthy saturated fats that go straight to the liver for a quick energy boost. Monk fruit - contains powerful antioxidants called mogrosides. Cinnamon - clinically proven to support healthy blood sugar levels AND healthy triglyceride levels. Vanilla Bean - loaded with minerals like magnesium, potassium, and calcium. Vanilla also has mood-boosting and energy enhancing effects on body. Zero alcohol use.

\section{References}

1. Rahul Hajare (2018) Safe Sex: The True Principal Health? Medical Research and Clinical Case Reports 1(2): 79-81.

2. Rahul Hajare (2018) There is no Cure for the Cancer of Stupidity. Organic \& Medicinal Chem IJ 5(1): 555655.

3. Rahul Hajare (2018) Why No More Apes Evolving Into Humans. Res Med Eng Sci 4(4).

4. Hajare R (2017) Process from Biosafety Working Style to Accreditation Trends Driving Self-financed Private Pharmacy Institution in Remote Areas Individuals in India. J Tradit Med Clin Natur 6: 230.

5. Rahul Hajare (2018) The biosafety against privately managed pharmacy institution in Savitribai Phule Pune University is not such a simple shot. Int J Nep \&Uro Dis 2(2): 6-7.

6. Rahul Hajare (2018) The True Principal Health and Investigation of The High Burnout Stages Experienced by Professors Working in Pharmacy Institutions Pune University and Related Factors: an Important Study. Medical Research and Clinical Case Reports 1(2): 66-72.

7. Rahul Hajare (2018) An Attempt to Eradicate Alcohol Dependency from Adult Men in Service Privately Managed Pharmaceutical Institutions in India. Toxicology and Applied Pharmacology Insights 1(1): 18001.

8. Rahul Hajare (2018) Instructional Teaching Strategy Can Boost an Activator of Students. J Yoga \&Physio 4(4): 1-2.

9. Rahul Hajare (2018) A short research on phenomenology of dysmenorrhea and health effects on the quality life in Pune suburban pharmaceutical institution. J Microbiol Exp 6(2):121-122.

10. Rahul Hajare (2018) Self-Explanatory Non-Funded Project Study of Dysmenorrhea and Impact on Quality of Life in Rajgad Dnyanpeeth's College of Pharmacy-SavitribaiPhule Pune University Pune. Developments Clin Med Pathol 1(1): 1-6. 
11. Rahul Hajare (2017) The Impact of Relocation and Transfer of naive B.Pharm Students to Adjacent Class room in Privately Managed Self finance Co-Educational Pharmaceutical Institute and Survey Investigation of Attitude towards Pharmaceutical Syllabus. Biomed J Sci\& Tech Res 1(1): 1-3.
12. Rahul Hajare (2017) Early Rising May Be Linked to Mental Health Issues in Institute of Pharmaceutical Science an Observational Study Draws Inference from a Legal to Cultural Principles through Independent Variables. Biomed J Sci\& Tech Res 1(1).

\section{(c) (1) \\ This work is licensed under Creative Commons Attribution 4.0 License}

To Submit Your Article Click Here:

Submit Article

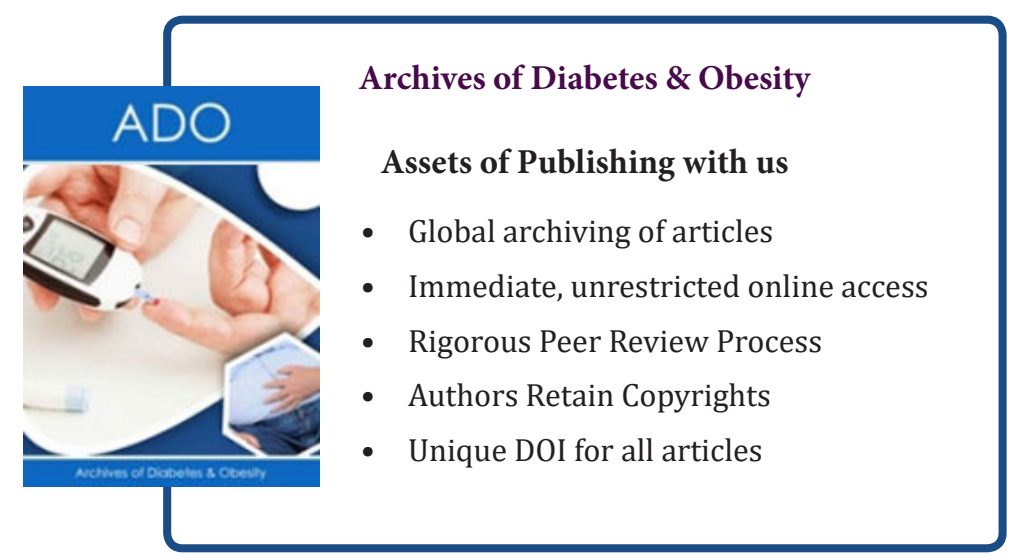

